\title{
Article \\ Identification and Functional Analysis of a Defensin CcDef2 from Coridius chinensis
}

\author{
Tao Gong, Juan Du, Shang-Wei Li *, Hai Huang (D) and Xiao-Lang Qi
}

check for updates

Citation: Gong, T.; Du, J.; Li, S.-W.; Huang, H.; Qi, X.-L. Identification and Functional Analysis of a Defensin CcDef2 from Coridius chinensis. Int. J. Mol. Sci. 2022, 23 , 2789. https://doi.org/10.3390/ ijms23052789

\section{Academic Editor: Michael Fromm}

Received: 31 January 2022

Accepted: 27 February 2022

Published: 3 March 2022

Publisher's Note: MDPI stays neutral with regard to jurisdictional claims in published maps and institutional affiliations.

Copyright: (C) 2022 by the authors. Licensee MDPI, Basel, Switzerland. This article is an open access article distributed under the terms and conditions of the Creative Commons Attribution (CC BY) license (https:// creativecommons.org/licenses/by/ $4.0 /)$.
Guizhou Provincial Key Laboratory for Agricultural Pest Management of Mountainous Regions, Institute of Entomology, Guizhou University, Guiyang 550025, China; gongtao458@163.com (T.G.); juandudj@163.com (J.D.); hh118545@163.com (H.H.); 18286176698@163.com (X.-L.Q.)

* Correspondence: swlii@163.com

\begin{abstract}
Coridius chinensis belongs to Dinidoridae, Hemiptera. Previous studies have indicated that C. chinensis contains abundant polypeptides with antibacterial and anticancer activities. Antimicrobial peptides (AMPs), as endogenous peptides with immune function, play an indispensable role in the process of biological development and immunity. AMPs have become one of the most potential substitutes for antibiotics due to their small molecular weight and broad-spectrum antimicrobial activity. In this study, a defensin CcDef2 from C. chinensis was characterized based on bioinformatics and functional analyses. The mature peptide of CcDef2 is a typical cationic peptide composed of 43 amino acid residues with five cations, and contains three intramolecular disulfide bonds and a typical cysteine-stabilized $\alpha \beta$ motif in defensins. Phylogenetic analysis showed that CcDef2 belongs to the insect defensin family. Analysis of gene expression patterns showed that CcDef2 was expressed throughout developmental stages of $C$. chinensis with high levels at the nymphal stage and in adult tissues tested with the highest level in the fat body. In addition, the CcDef2 expression was significantly upregulated in adults infected by bacteria. After expressed in Escherichia coli BL21(DE3) and renatured, the recombinant CcDef2 showed a significant antibacterial effect on three kinds of Gram-positive bacteria. These results indicate that CcDef2 is an excellent antibacterial peptide and a highly effective immune effector in the innate immunity of $C$. chinensis. This study provides a foundation for further understanding the function of $C c D e f 2$ and developing new antimicrobial drugs.
\end{abstract}

Keywords: Coridius chinensis; antimicrobial peptide; defensin; innate immunity; antibacterial activity

\section{Introduction}

Multicellular organisms are constantly infected by pathogens and parasites in the surrounding environment, and the immune system can help them resist the invasion of bacterial pathogens. Insects have no specific immune system similar to vertebrate Tlymphocytes and B-lymphocytes, so innate immunity is the only way for insects to face pathogen infection $[1,2]$. Insect innate immunity mainly consists of humoral immunity and cellular immunity. Humoral immune responses include the production of antimicrobial peptides (AMPs), reactive intermediates of oxygen or nitrogen, and the complex enzymatic cascades that regulate coagulation or melanization of hemolymph [3-6]. Cellular responses refer to the immune response mediated by blood cells, including phagocytosis, nodulation, and encapsulation $[7,8]$. As a requisite part of the humoral immune mechanism, AMP is the first barrier of host defense and can kill bacteria, fungi, viruses, and protozoa or slow down their growth $[9,10]$.

AMPs may be classified into four groups based on the differences in amino acid composition and structural characteristics: cecropin, defensin, glycine-rich peptides, and proline-rich peptides [11]. Cecropin was the first insect AMP that was isolated from the hemolymph of the pupae of Hyalophora cecropia. [12]. Since then, cecropins have been isolated from Bombyx mori, Antherea pernyi, Drosophila, and Sarcophagidae. The isolation 
of cecropin P1 from the small intestine of pigs indicated that cecropin may be widely present in animals [13]. The glycine-rich antimicrobial peptides were found in some insects, such as coleoptericin from Allomyrina dichotoma and hemiptericin from Pyrrhocoris apterus [14,15]. The proline-rich antibacterial peptides were reported in Italian bees [16,17] and Drosophila [18]. Defensin was found in polymorphonuclear neutrophils of mice and guinea pigs, initially named lysosomal cationic protein [19], and later defined and described as defensin in 1985 [20]. Two antibacterial peptides against Gram-positive bacteria isolated from larvae of Phormia terranovae were named insect defensins in 1989, based on their similarity to mammalian defensins [21,22]. Insect defensins are natural immune polypeptides produced by the fat body and hemolymph during accidental injury and invasion of pathogenic microorganisms, and are widely distributed in various insect orders such as Diptera, Hymenoptera, Odonata, Hemiptera, Lepidoptera, and Coleoptera. The defensins mainly act against Gram-positive bacteria, but some are also effective against Gram-negative bacteria or fungi. It has also been reported that insect defensins have antiviral and antitumor activities [23,24].

The emergence of antibiotic-resistant pathogens worldwide has become one of the severe threats to public health. The infection of drug-resistant bacteria is becoming more common and some pathogens are even resistant to various types of antibiotics. AMPs are considered as one of the most promising alternatives to antibiotics because of their particular antimicrobial mechanism by which bacteria are not easy to develop drug resistance [25]. As far as defensins are concerned, they can exert antibacterial effect by interacting with the negatively charged bacterial cell membrane, which has no specificity $[26,27]$. If bacteria are to be resistant to defensins, they must reshape the structure of their cell membrane. In addition, unlike the classical antibiotics that must penetrate the target cells to act on them, AMPs are thought to kill the target cells by destroying their cell membranes [28]. Theoretically, this mode of action will seriously reduce the resistance of microorganisms.

Our previous studies have revealed that the hemolymph of $C$. chinensis has broadspectrum antibacterial activity that is caused mainly by AMPs in this insect [29]. In this study, a defensin CcDef2 gene was identified from the full-length transcriptome of C. chinensis and verified by polymerase chain reaction (PCR) and Sanger sequencing. Sequence analysis and phylogenetic tree construction elucidated the evolutionary relationship between CcDef2 and other defensins. The spatiotemporal expression profile of CcDef2 was analyzed at different developmental stages and in various tissues of adults by using realtime quantitative PCR (RT-qPCR). We analyzed the expression levels of CcDef2 in adults injected with bacteria, which further revealed the role of CcDef2 in the innate immunity of $C$. chinensis. CcDef2 was successfully expressed in E. coli BL21 (DE3) and was shown to have the antibacterial effect by using a bacterial growth inhibition test. This study not only enriched the diversity of AMPs but also provided the theoretical feasibility for the development and utilization of AMPs in C. chinensis.

\section{Results}

\subsection{Characteristic Analysis of CcDef2}

The CcDef2 cDNA is 859 bp in length (GeneBank accession numbers: MN816377), containing an ORF of $351 \mathrm{bp}$ that encodes 116 amino acid residues (AAs), a $5^{\prime}$ untranslated region (UTR) of $38 \mathrm{bp}$, and a $3^{\prime}$ UTR of $470 \mathrm{bp}$ UTR with a polyadenylation tailing signal $\left(5^{\prime}\right.$ AATAAA $3^{\prime}$ ) (Figures 1 and 2). CcDef2 contains a signal peptide of 17 AAs and two precursor peptides of 30 and 26 AAs at the N-terminus with three cleavage sites $\left(\mathrm{A}_{17} \downarrow \mathrm{I}_{18}\right.$, $R_{47} \downarrow S_{48}$, and $\left.R_{73} \downarrow A_{74}\right)$; therefore, its mature peptide consists of 43 AAs (Figure 2 ). The mature CcDef2 is a typical cationic peptide containing five positive charges, with a molecular weight of $4.70 \mathrm{kDa}$ and a theoretical isoelectric point of 9.10. Structural analysis showed that the mature $\mathrm{CcDef} 2$ can form an $\alpha$-helix and two $\beta$-pleated sheets as well as three intramolecular disulfide bonds $\left(C_{76}-C_{107}, C_{93}-C_{112}\right.$, and $\left.C_{97}-C_{114}\right)$ formed by six cysteines. Homology modeling showed that the $\beta$-pleated sheet at the C-terminus of mature CcDef2 connected with the $\alpha$-helix through two disulfide bonds to form a cysteine-stable $\alpha \beta$ motif 
(CS $\alpha \beta$ motif) and with the $\mathrm{N}$-terminal via another disulfide bond to form a ring (Figure $3 \mathrm{a}$ ). It is generally believed that the stable $\alpha$-helix and $\beta$-sheet conformation is a functional structure for defensin to exert antibacterial activities. In addition, six cysteine residues and the eight other conserved AAs (Ala74, Thr75, Asp77, Ser80, Ala94, Gly104, Gly105, and Arg115) form a substrate-binding groove among the $\alpha$-helix and $\beta$-sheets of mature CcDef2 (Figure $3 b$ ). CcDef2 also shows the distribution of positive charges (six basic amino acids) in the surface of the three-dimensional molecular structure (Figure 3c). Electrostatic surface analysis revealed that several regions in the surface of the solution structure were positively charged at a neutral $\mathrm{pH}$ (Figure 3c, in blue). Taken together, CcDef2 has the structural and electrostatic properties of insect defensins.

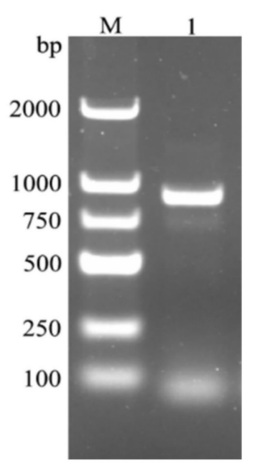

Figure 1. PCR amplification product of $C c D e f 2$ from C. chinensis. M: DL2000 DNA marker. 1: PCR product of CcDef2.

(a)

\begin{tabular}{|c|c|}
\hline & ACGCTTCAGTTGAGTCCATCTCTAGCAGGTCATCAATCATGAAGGTGTTAGTCGTATTTGCAGCTGTCGCTGTT \\
\hline 1 & $\begin{array}{lllllllllllll} & M & K & V & L & V & V & F & A & A & V & A & V\end{array}$ \\
\hline & GTCTACATCGGTGCTATCCCAGTCTTCGAGGAGCAGTTGGGAGAACTTCCTTATGAGATTTATGAAGACGATC \\
\hline 13 & 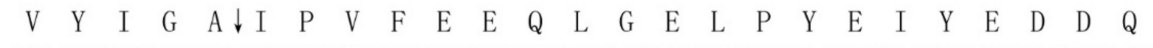 \\
\hline & ACAGCAGGCGATCAAATCCGCCATACGAGGTCAGCTTTTGAGACATACCACGAAGAAGAGCCGTTGGAAGATACT \\
\hline 38 & 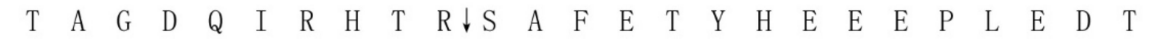 \\
\hline & GAAGAACTCACACAGGGACTGAGGCTGAAAAGAGCCACTTGCGACGCACTCAGCTTCCAATCCAAGTGGATCACC \\
\hline 63 & 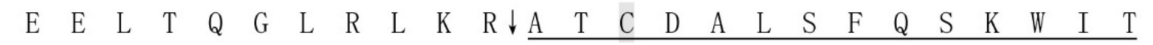 \\
\hline & ATAAACCACTCAGCATGCGCCATCCACTGCATCGCCAAAGGATACAAGGGTGGTCAATGTAAGAACACTGTCTGT \\
\hline 88 & $\begin{array}{lllllllllllllllllllllllll}\mathrm{I} & \mathrm{N} & \mathrm{H} & \mathrm{S} & \mathrm{A} & \mathrm{C} & \mathrm{A} & \mathrm{I} & \mathrm{H} & \mathrm{C} & \mathrm{I} & \mathrm{A} & \mathrm{K} & \mathrm{G} & \mathrm{Y} & \mathrm{K} & \mathrm{G} & \mathrm{G} & \mathrm{Q} & \mathrm{C} & \mathrm{K} & \mathrm{N} & \mathrm{T} & \mathrm{V} & \mathrm{C} \\
\end{array}$ \\
\hline & CACTGCAGGAAGTAGAGGAAAGGATCCAAATTTGAATACTCCAAAGCCCACTGATACCAAATTTGTATAACTTAG \\
\hline 1. & $\begin{array}{lllll}\mathrm{H} & \mathrm{C} & \mathrm{R} & \mathrm{K} & *\end{array}$ \\
\hline & ATCTGATTTTATAAA \\
\hline & ATTAAAATTTTTAA \\
\hline & CAAGAATATTAGGTTTAAATGAAATAAAAGGTACAAATATCCT \\
\hline & AATAGGTAGTAATAACTGACAGAAATGAACTGAATGAGATAAACTTAAATGA \\
\hline & TTGTAGGCTTTAACATTACTACCAATTTTCCTCTTAAAGATTATGTATA \\
\hline & 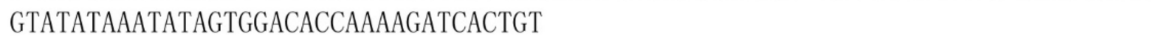 \\
\hline
\end{tabular}

(b)

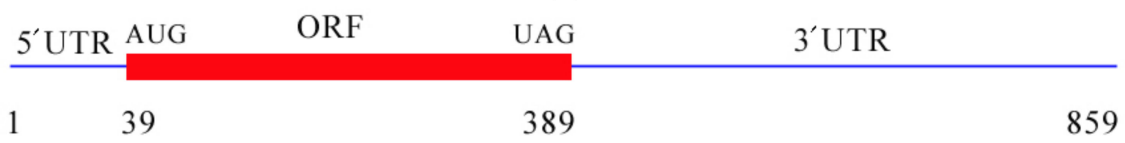

Figure 2. Nucleotide sequence, mRNA, and deduced amino acid sequence of CcDef2. (a) Nucleotide and amino acid sequences of CcDef2. (b) Schematic diagram of the CcDef2 mRNA. The amino acid sequence of the mature CcDef2 is marked by a single underline. The star codon (ATG) is marked by a box. The polyadenylation signal is indicated with a double underline. The asterisk indicates the stop codon (TAG). Vertical arrows indicate the cleavage sites of signal peptide and precursor peptide. Six cysteines are marked with gray shade. The $5^{\prime}$ untranslated region (UTR) contains the 1st to 38th nucleotides and the $3^{\prime}$ UTR contains the 390th to 859th nucleotides. 


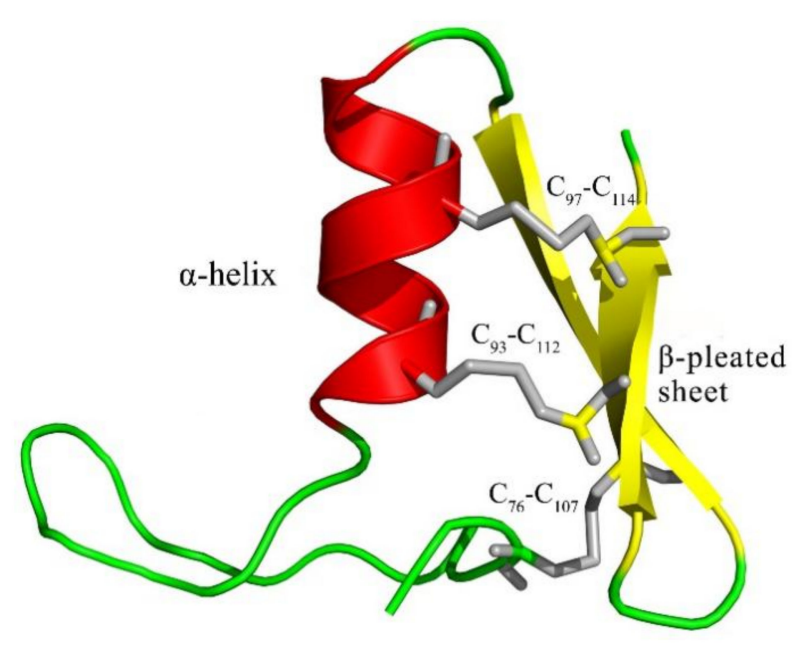

(a)

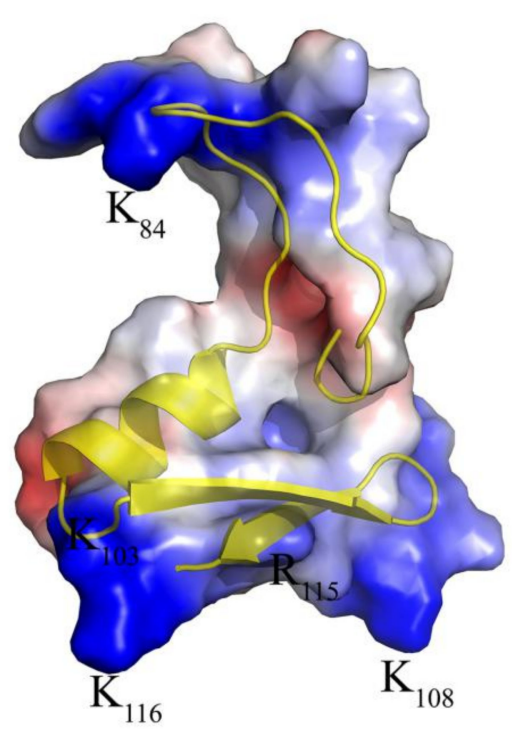

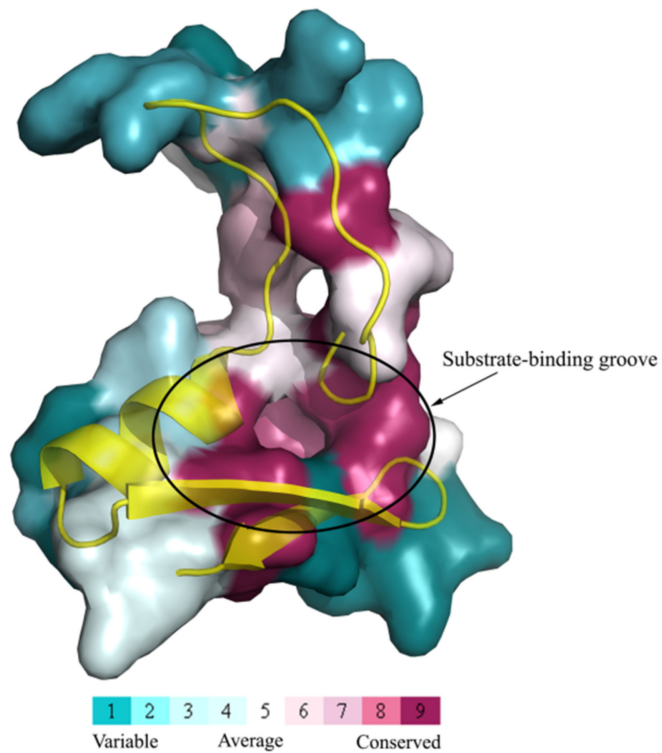

(b)

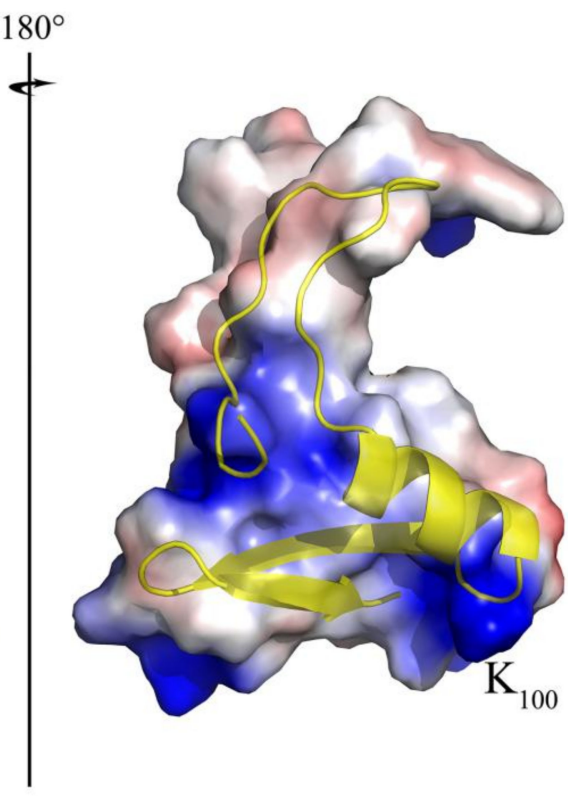

(c)

Figure 3. Three-dimensional molecular structure of the mature CcDef2. (a) This figure is generated with PyMOL 2.4 based on the $C_{c}$ Def2.pdb data. $C_{76}-C_{107}, C_{93}-C_{112}$, and $C_{97}-C_{114}$ indicate disulfide bonds. (b) The evolutionary conservation of amino acid positions in the mature CcDef2 based on the phylogenetic relations between homologous sequences. Conserved residues are displayed in fuchsin in the structure. Homology modeling was performed with the ConSurf software (https: / / consurf.tau.ac.il/) (accessed on 15 March 2021) and optimized by using PyMOL 2.4. (c) Electrostatic potential map of the mature CcDef2. The positively charged regions and negatively charged regions are shown in blue and red, respectively.

\subsection{Multiple Sequence Alignment and Phylogenetic Analysis}

Multiple sequence alignment indicated that insect and mammal defensins had six conserved cysteine residues, while plant defensins had eight ones. Interestingly, previous studies found that insect defensins were highly homologous with plant defensins [30]. Positions of cysteines between insect and plant defensins are similar but quite different 
from mammalian defensins (Figure 4). In addition, two typical characteristics of the mature peptides of most insect defensins are the presence of an alanine residue and a threonine residue $(-\mathrm{AT}-)$ at the $\mathrm{N}$-terminus, and the presence of an arginine residue $(-\mathrm{R}-)$ at the C-terminus (Figure 4). CcDef2 and CcDef3 were highly homologous with $78.45 \%$ sequence similarity; however, CcDef2 shared only $46.55 \%$ similarity with CcDef and $44.83 \%$ with CcDef1 using ClustalW algorithm (CcDef and CcDef1, 94.12\% similarity).

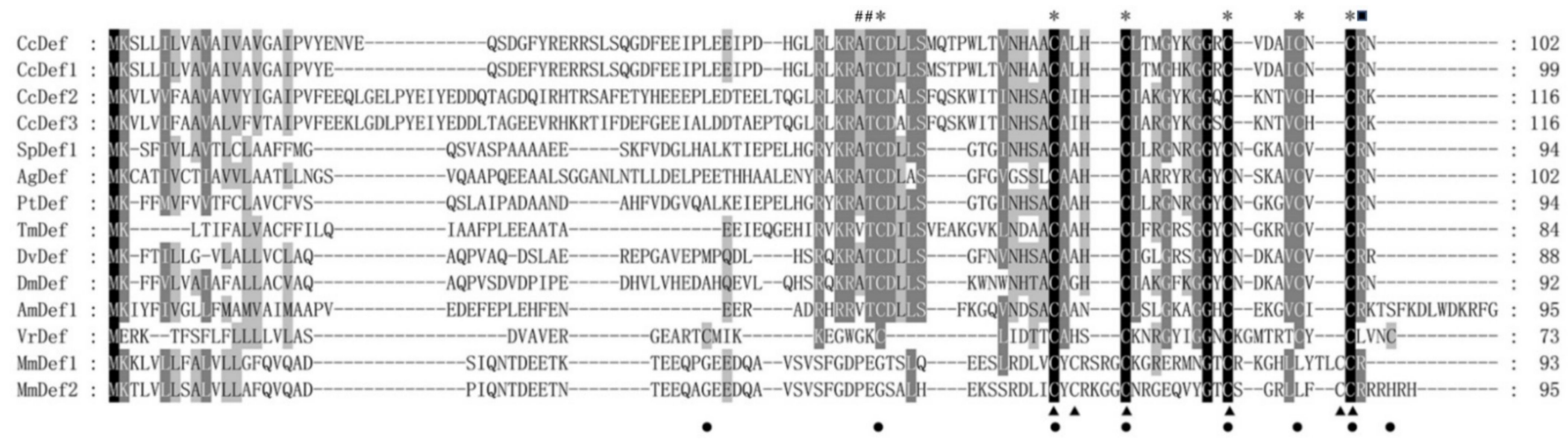

Figure 4. Multiple sequence alignment of four defensins from C. chinensis and typical defensins from other species. These species include seven insects: Sarcophaga peregrina (SpDef1), P18313; Anopheles gambiae (AgDef), Q17017; Protophormia terraenovae (PtDef), P10891; Tenebrio molitor (TmDef), Q27023; Drosophila virilis (DvDef), AHW49172; Drosophila melanogaster (DmDef), P36192 and Apis mellifera (AmDef1), P17722; a plant Vigna radiata (VrDef), AAR08912 and two mammals Mus musculus (MmDef1, NP_034161; and MmDef2, NP_001182563). Asterisks indicate positions of cysteines in insect defensins, solid triangles represent positions of cysteines in mammalian defensins, and solid circles denote positions of cysteines in plant defensins. \#: Pounds indicate alanine (A) and threonine $(\mathrm{T})$, and the black box marks arginine (R).

The phylogenetic tree shows that insect defensins group into a branch and different from mammal and plant defensins (Figure 5). Defensins from Diptera and Coleoptera cluster into a clade and those from Hemiptera and Hymenoptera fall into another clade. As shown in Figure 5, four defensins from C. chinensis form two subtypes. Interestingly, in a homology search it was found that CcDef2 and other homologues sequenced in insects also fell into two subtypes (https: / / www.ncbi.nlm.nih.gov, accessed 10 January 2022). During evolution, CcDef2 and CcDef3 have the closest homologue with defensin from Pyrrhocoris apterus (PaDef). 


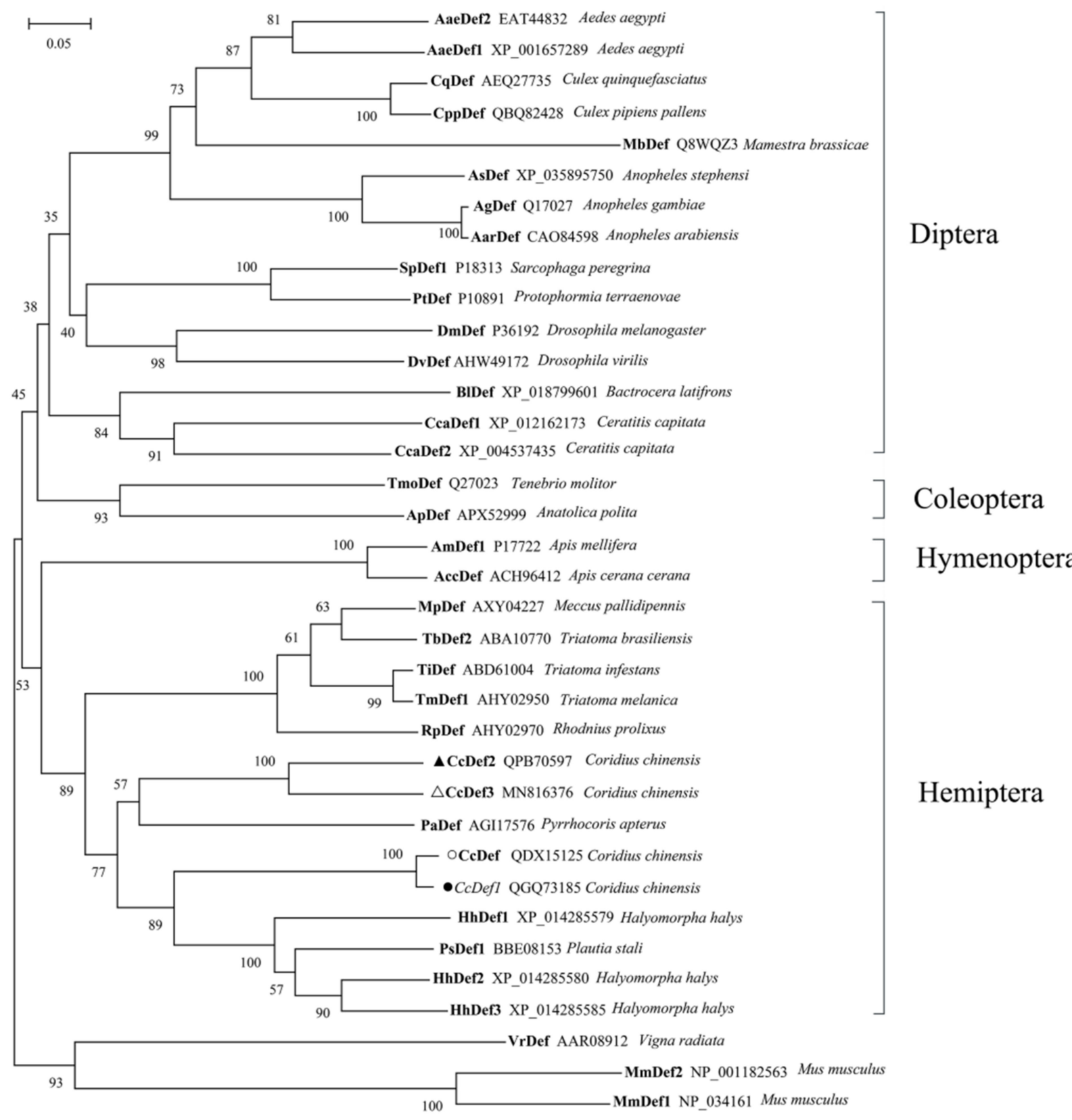

Figure 5. A cluster dendrogram of 36 defensins from 28 species. This tree was constructed using MEGA $X$ based on the neighbor-joining method (NJ). One thousand replicates were performed and bootstrap confidence values are shown at the nodes of this tree. Defensins from Vigna radiata (VrDef) and Mus musculus (MmDef1 and MmDef2) are used as outgroups. Four defensins from C. chinensis are marked with a filled circle, a circle, a filled triangle, and a triangle, respectively.

\subsection{Spatiotemporal Expression Profile}

The RT-qPCR results indicated that CcDef2 was expressed throughout developmental stages of $C$. chinensis, with the highest level in the fifth-instar nymph, followed by the third- and fourth-instar nymphs, and with relatively low levels at other stages. There were no significant differences in CcDef2 expression levels among the eggs, first- and second-instar nymphs, and female and male adults. The CcDef2 expression level in the fifth-instar nymph was 180.70 times that in the egg and 2.66 times that in the third-instar nymph (Figure 6a). In general, AMPs are expressed in the fat body and secreted into the hemolymph to protect insects from the invasion of microorganisms. The CcDef2 gene was expressed in the seven adult tissues tested, with higher expression levels in the fat body 
and hemolymph compared with the other tissues (Figure 6b). The highest expression of CcDef2 in the fat body implies that it may be a very important immune tissue in innate immunity of $C$. chinensis.

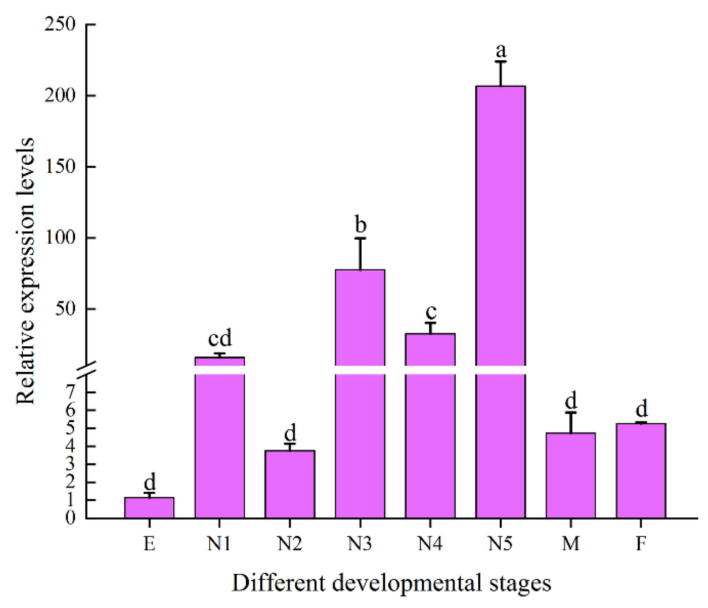

(a)

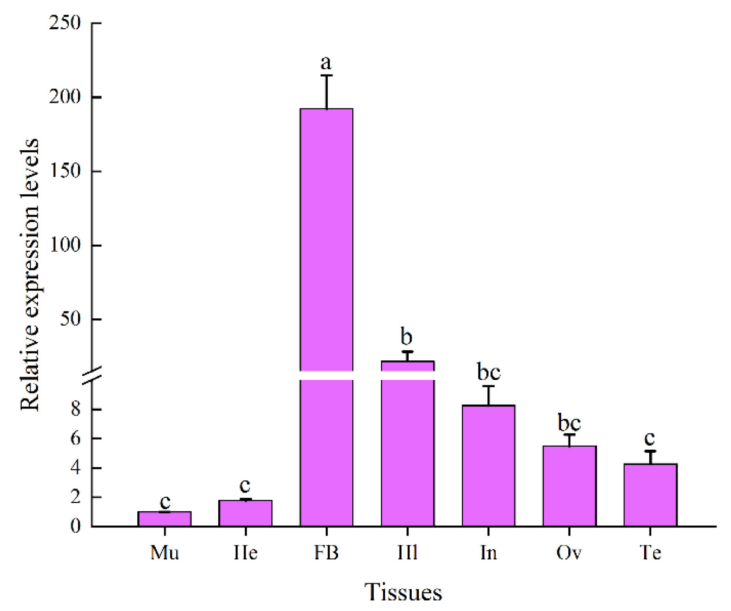

(b)

Figure 6. Relative expression levels of CcDef2 at different developmental stages (a) and in various tissues of C. chinensis adults (b). (a) E: egg; N1-N5: first-fifth-instar nymphs; M: male; F: female. The adults come from different male and female individuals. (b) Mu: muscle; He: head; FB: fat body; Hl: hemolymph; In: integument; Ov: ovary; Te: testis. Values are the mean $\pm \mathrm{SD}$ of three replicates. Differences between groups were analyzed using one-way ANOVA and Duncan's multiple range test. Different lowercase letters above the columns indicate significant differences ( $p<0.05$, Duncan's test).

\subsection{Expression Patterns of CcDef2 upon Bacterial Challenge}

The expression levels of CcDef2 were detected by using RT-qPCR in adults challenged by $S$. aureus and E. coli. The CcDef2 expression was upregulated 6-36 h after bacterial challenge and slightly declined at $48 \mathrm{~h}$. The CcDef2 expression level $12 \mathrm{~h}$ post injection was 56.89 times that without infection (Figure 7a). In the fat body from adults, we also observed a 40.28-fold increase in CcDef2 expression level (Figure 7b). The changes implied that CcDef2 was involved in the immune response to bacterial infection.

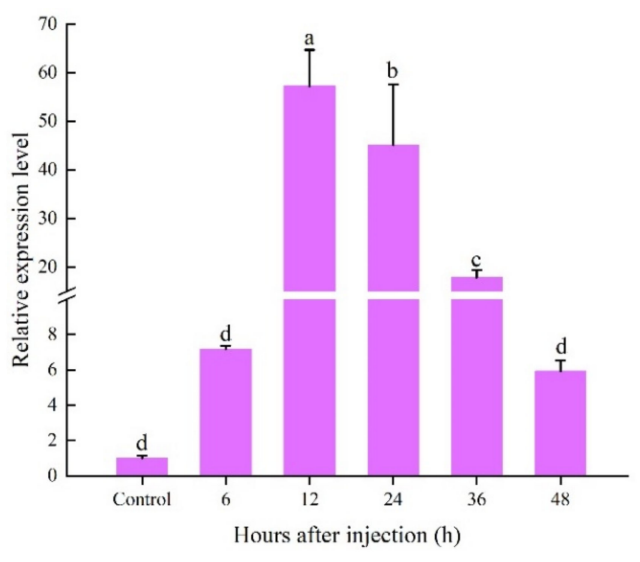

(a)

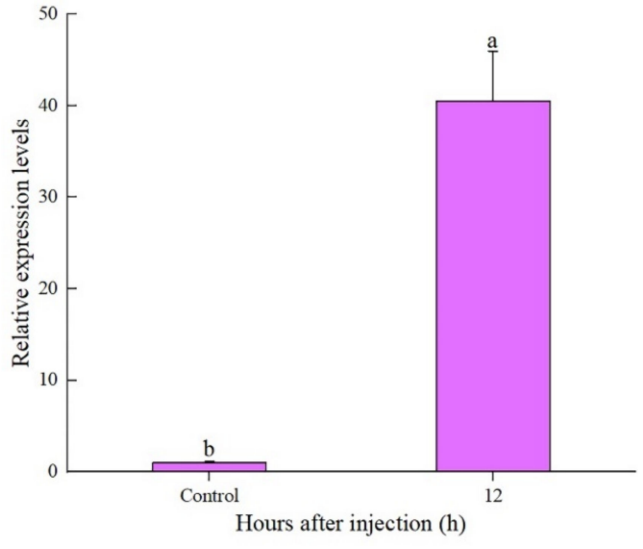

(b)

Figure 7. Expression levels of CcDef2 at different times upon bacterial infection. (a) C. chinensis adults. (b) The fat body from adults. Healthy adults were infected with phosphate-buffered saline (PBS) as the control. Data are represented as the mean \pm SD of three replicates. Differences between groups were analyzed using one-way ANOVA and Duncan's multiple range test. Different lowercase letters above the columns indicate significant differences ( $p<0.05$, Duncan's test). 


\subsection{Expression Analysis of Recombinant Protein}

The nucleotide sequence of the mature CcDef2 was optimized according to the preference of codon usage in E. coli, and the optimized sequence is shown in Figure S1. By predicting, the theoretical molecular weight is about $18.2 \mathrm{kDa}$ for the recombinant CcDef2 protein. SDS-PAGE displayed a target protein band at about $20 \mathrm{kDa}$ in inclusion bodies recovered from $E$. coli cell lysates and this band was very close to the predicted molecular weight of the recombinant CcDef2 protein (Figure 8a), which was purified from the inclusion bodies by using the $6 \times$ His tag and Ni-NTA resin, a single clear band appearing at $20 \mathrm{kDa}$ (Figure 8b). Western blot also showed a band of approximately $20 \mathrm{kDa}$ (Figure 8c). These results indicated that the recombinant CcDef2 protein had been successfully expressed. The concentration of recombinant CcDef2 protein was $0.8 \mathrm{mg} / \mathrm{mL}$ based on the test result with the BCA method.

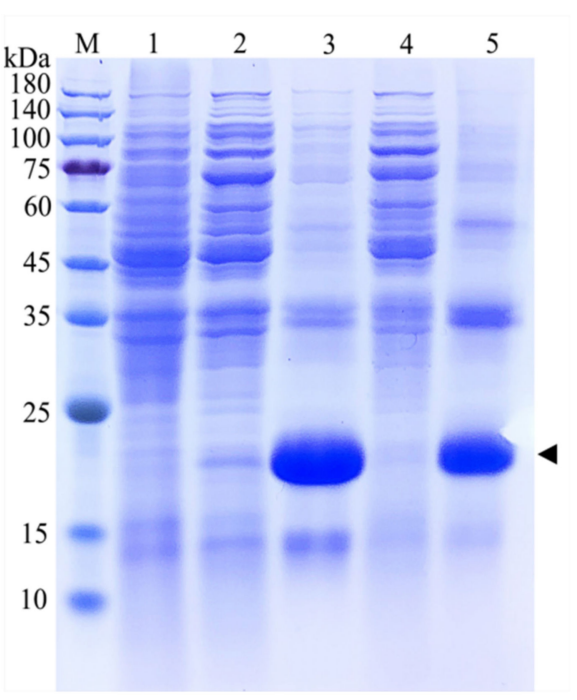

(a)

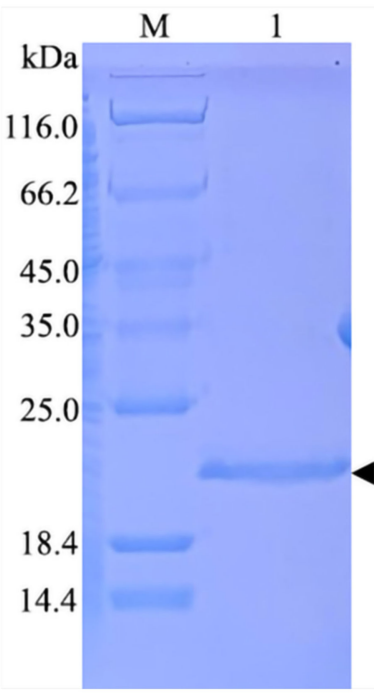

(b)

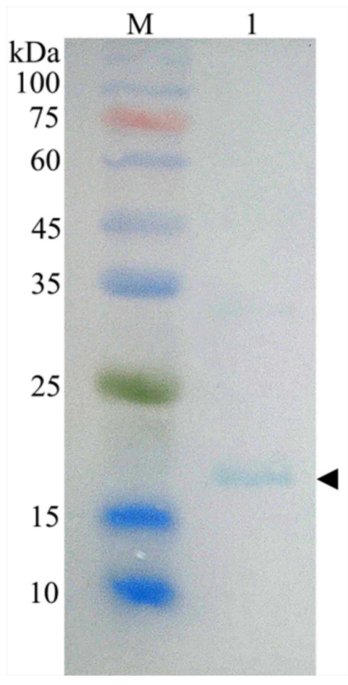

(c)

Figure 8. Identification of the recombinant CcDef2 protein. (a) SDS-PAGE analysis of the recombinant CcDef2 expressed by E. coli induced. Lane 1: the non-induced bacterial culture. Lanes 2 and 4: the soluble supernatant. Lines 3 and 5: inclusion bodies. (b) Purification of the recombinant CcDef2. Lane 1: fusion CcDef2. (c) Verification of the recombinant CcDef2 by Western blot. Lane 1: the blotting band of the fusion CcDef2 protein. M: Protein molecular weight markers. The arrowheads indicate the bands of the recombinant CcDef2 proteins.

\subsection{Antibacterial Spectrum and MIC}

The results of antibacterial assay indicated that CcDef2 exhibited the antibacterial activities against the tested Gram-positive bacteria, i.e., S. aureus, M. luteus, and B. subtilis, but had no effects on the tested Gram-negative bacteria, i.e., P. aeruginosa, E. coli, and S. typhi (Figure 9). The findings are similar to those from most insect defensins. Remarkably, the recombinant CcDef2 had an obvious antibacterial effect on $S$. aureus compared with the controls. The minimum inhibitory concentration (MIC) of the recombinant CcDef2 against $S$. aureus was $50 \mu \mathrm{g} / \mathrm{mL}(0.92 \mu \mathrm{M})$ and the amount of bacteria incubated for $18 \mathrm{~h}$ was significantly lower than the control when the final concentration of the recombinant CcDef2 reached $6 \mu \mathrm{g} / \mathrm{mL}$ (Figure 10). MICs of the recombinant CcDef2 against M. luteus and B. subtilis were $1.24 \mu \mathrm{M}$ and $1.56 \mu \mathrm{M}$, respectively (Table 1). 


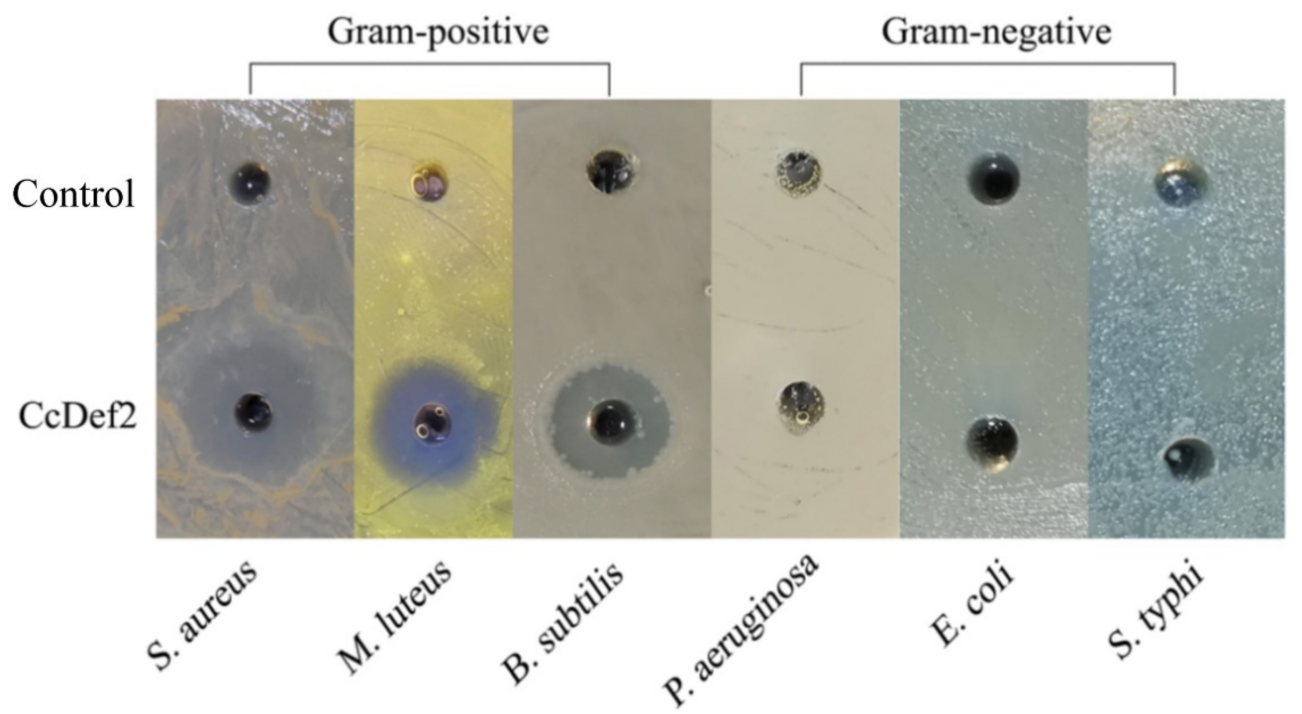

(a)

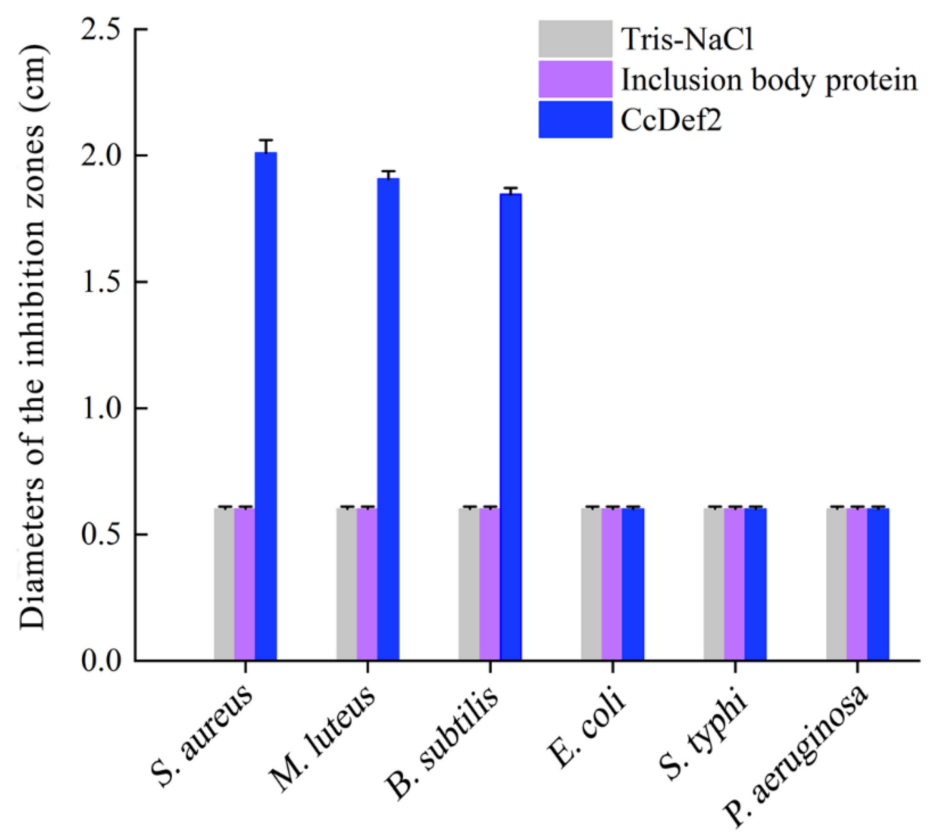

(b)

Figure 9. Antibacterial activity of the recombinant CcDef2. (a) Inhibition zones of CcDef2 against six kinds of bacteria. (b) Diameters of the inhibition zones. Tris- $\mathrm{NaCl}$ buffer was used as the control. The non-refolded inclusion body was used as a negative control. For the plate without a lytic zone, the diameter of a hole was used to represent the one of a lytic zone $(0.6 \pm 0.01 \mathrm{~cm})$. Data are expressed as the mean $\pm \mathrm{SD}$ of three replicates. 


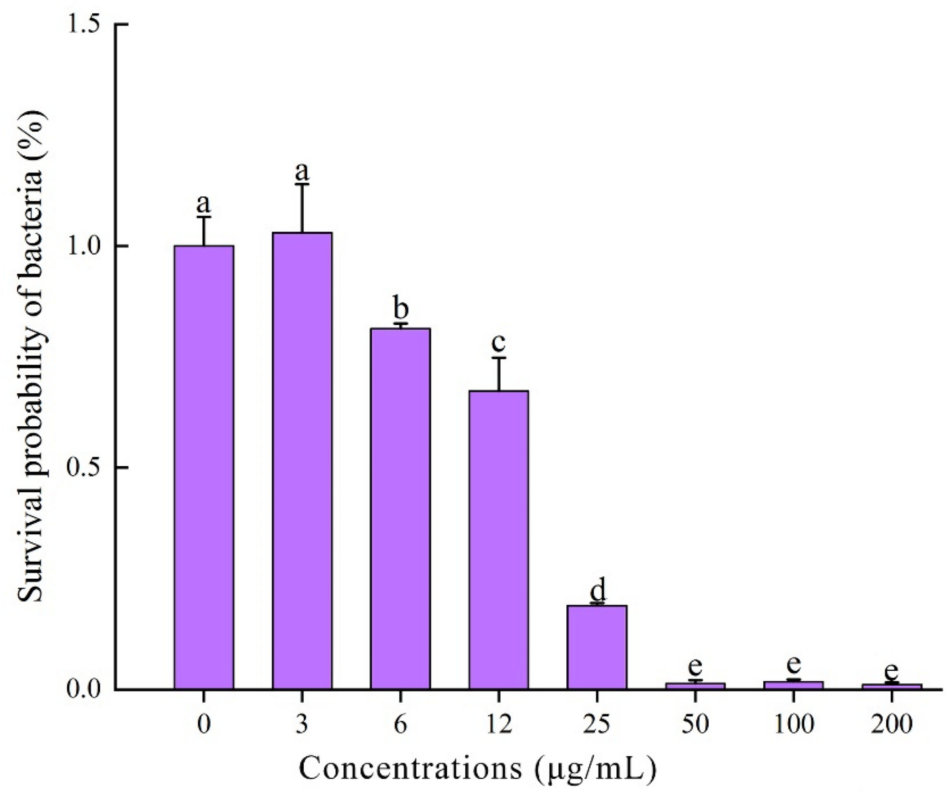

Figure 10. The MIC of the recombinant CcDef2 against $S$. aureus. Data are expressed as the mean \pm SD of three replicates. Differences between groups were analyzed using one-way ANOVA and Duncan's multiple range test. Different lowercase letters above the columns indicate significant differences $(p<0.05$, Duncan's test).

Table 1. Minimum inhibitory concentrations of the recombinant CcDef2.

\begin{tabular}{cc}
\hline Bacterial Strain & MIC $(\mu \mathbf{M})$ \\
\hline Gram-positive bacteria & \\
\hline S. aureus ATCC 25923 & 0.92 \\
M. luteus CMCC 28001 & 1.24 \\
B. subtilis CMCC 63501 & 1.56 \\
Gram-negative bacteria & \\
E. coli ATCC 25922 & ND \\
P. aeruginosa CMCC 10104 & ND \\
S. typhi CMCC 50071 & ND \\
\hline
\end{tabular}

Notes: ND, no detectable activity. Data are expressed as the mean.

\section{Discussion}

Insect defensins were originally purified in S. peregrina [31]. They are antimicrobial peptides with potent activity against Gram-positive bacteria and weak activity against Gram-negative bacteria and fungi. So far, most defensins isolated and identified from insects are cationic peptides [32]. In this study, the cDNA sequence of CcDef2 was cloned and confirmed by using RT-PCR and sequencing. The mature peptide of CcDef2 shares the similar sequence and structural characteristics as most insect defensins. Typical motifs of insect defensins are $C-\times 5-16-C-\times 3-C-\times 9-11-C-\times 4-7-C-\times 1-C$, which contain $34-51$ amino acids [33]. Generally, six cysteines in an insect defensin form three intramolecular disulfide bonds that consist of Cys1-Cys4, Cys2-Cys5, and Cys3-Cys6. In addition, the $\beta$-pleated sheet of a mature insect defensin connects with the $\alpha$-helix through two disulfide bonds to form a stable $\mathrm{CS} \alpha \beta$ motif. The $\mathrm{CS} \alpha \beta$ motif is an important spatial structure of defensins and is closely related to the structural stability and antibacterial activity [34-36]. The motif of CcDef2 is $\mathrm{C}-\times 16-\mathrm{C}-\times 3-\mathrm{C}-\times 9-\mathrm{C}-\times 4-\mathrm{C}-\times 1-\mathrm{C}$ and is consistent with the typical one of a defensin. Significantly, CcDef2 is also a typical cationic peptide and its mature peptide contains five cations. Typical insect defensins are positively charged ones that can combine with negatively charged microbial cell membrane components through the mutual attraction to produce antibacterial effect [37]. 
The defensin gene found in D. melanogaster is single copy and lacks intron [38]. It was inferred that the insect defensins evolved independently. Subsequently, it was discovered that insect and mammalian defensins were different in disulfide bond connection and three-dimensional configuration, indicating that they were not homologous. Interestingly, Thevissen et al. demonstrated that defensins from insects and plants interacted with fungal glucosylceramides and they had high homology [39]. A variety of insect defensins indicate that insects have diverse immune mechanisms. At least two defensin homologues are usually found in many sequenced insect genomes or transcriptomes. In the transcriptome data of $C$. chinensis, we found four different defensin homologues that could be divided into two subtypes based on the phylogenetic analysis. CcDef2 and CcDef3 are highly homologous but different from CcDef and CcDef1, which may be the result of the finely tuned immune responses to counter pathogens and the adaptive evolution against pathogens in $C$. chinensis. Some studies suggested that the $C S \alpha \beta$ motif of insect defensins evolved by gene duplication, followed by divergence due to selective evolutionary pressure, thus resulting in a diverse set of paralogues [40].

Previous studies have demonstrated that the expression pattern of insect AMP genes is regulated by their growth and development. The expression levels of three defensing genes ( $A g D e f 2, A g D e f 3$, and $A g D e f 4)$ from A. gambiae were almost undetectable in the eggs, pupae, and adults, but were high in the larvae [41]. Similarly, the CcDef2 expression levels in the nymphs were much higher than those in the eggs and adults. The AMP BhSGAMP-1 from Bradysia hygida was specifically expressed in the salivary glands of the larvae when they were preparing to molt, thus preventing microbial infection [42]. In this study, CcDef2 was expressed in nymphs at high levels. We speculated that this may be due to the fact that an insect is more susceptible to infection by pathogens during molting, so C. chinensis nymphs improve the ability to resist the invasion of pathogens by increasing expression levels of CcDef2. In general, after infection or injury, insect AMPs are expressed in the fat bodies and secreted into hemolymph to protect insects from pathogenic microorganisms $[43,44]$. Similar to previous studies, the expression levels of CcDef2 in the fat body were much higher than those in other tissues, indicating that the fat body is a vitally important immune tissue for $C$. chinensis in the process of resisting infection. Since the immune effectors are believed to be upregulated in response to infection, the mRNA expression levels of CcDef2 were analyzed after bacterial challenge. AMP would appear in the hemolymph of infected insects about 6-12 h after infection [45]. As expected, the expression levels of CcDef2 gene was significantly upregulated post bacterial challenge, suggesting that CcDef2 is closely associated with the immune response of $C$. chinensis against bacterial infection.

AMPs, known as the evolutionary ancient immune weapons, are the natural defense barriers of most organisms against the invasion of pathogens [46]. As a part of non-specific immune response, AMPs are directly involved in various immune responses to pathogens and perform broad-spectrum activity against various pathogenic microorganisms, such as Gram-positive bacteria, Gram-negative bacteria, enveloped viruses, and fungi [47]. Insect defensin, a main member of AMP, has always been an important subject in AMP research. At present, plenty of studies have been conducted to evaluate the antibacterial activity of insect defensins. The canonical antibacterial mechanism of defensins is that they interact with negatively charged bacterial membranes and insert into membrane bilayers to form pores, leading to membrane permeabilization and disruption [48]. In general, defensins are known to be active mainly against Gram-positive bacteria at various concentrations (MICs range from $0.4 \mu \mathrm{M}$ to $100 \mu \mathrm{M}$ ) [49,50], but their activity against Gramnegative bacteria is weak because of the inability to penetrate the outer membrane of the bacteria [51-55]. Like most insect defensins, the recombinant CcDef2 produced inhibitory effects on Gram-positive bacteria (MICs range from $0.92 \mu \mathrm{M}$ to $1.56 \mu \mathrm{M}$ ) but exhibited no inhibitory effects on such Gram-negative bacteria like E. coli. However, mammalian and plant defensins have been demonstrated to possess broad-spectrum antibacterial activity against both Gram-negative and Gram-positive bacteria [56-59]. AMPs diverge due to 
selective evolutionary pressure during the long-term evolution of insects and their functions also undergo corresponding fine-tuning and differentiation.

\section{Materials and Methods}

\subsection{Insects and Bacteria}

The laboratory populations of $C$. chinensis were collected from Guiyang, Guizhou, China, in 2019, and were reared at $28 \pm 1{ }^{\circ} \mathrm{C}$ and a $75 \pm 5 \%$ relative humidity under a 14:10 $\mathrm{h}$ light:dark photoperiod in the insectary of the Institute of Entomology, Guizhou University. Both nymphs and adults were fed with fresh pumpkin leaves. Escherichia coli BL21 (DE3) cells with 20\% glycerol and expression vector pET-28b(+) (Merk KGaA, Damstadt, Germany) are kept at $-80^{\circ} \mathrm{C}$ in our laboratory. E. coli (ATCC 25922), Salmonella typhi (CMCC 50071), Pseudomonas aeruginosa (CMCC 10104), Micrococcus luteus (CMCC 28001), Bacillus subtilis (CMCC 63501), and Staphylococcus aureus (ATCC 25923) are kept in our laboratory.

\subsection{RNA Extraction and Gene Cloning}

An HP Total RNA Kit (Omega Bio-Tek Inc., Norcross, GA, USA) was used to extract the total RNA from different developmental stages (the eggs, first-fifth-instar nymphs, and females and males) and from various tissues (the head, integument, fat body, hemolymph, testis, ovary, and muscle) of $C$. chinensis adults. The hemolymph was extracted by using the double-tube centrifugation [60]. The purity and concentration of RNA were determined with a NanoDrop 2000 spectrophotometer (Thermo Fisher Scientific, Waltham, MA, USA) and the quality of RNA was detected by using 1\% agarose gel electrophoresis. RNA was used as a template to synthesize cDNA using a RevertAid First Strand cDNA Synthesis Kit (Thermo Fisher Scientific, Waltham, MA, USA). The synthesized cDNA was diluted to $400 \mathrm{ng} / \mu \mathrm{L}$ and stored at $-20^{\circ} \mathrm{C}$. Based on the transcriptome sequence information, primers for the reverse transcription-PCR (RT-PCR) primers were designed with Primer Premier 6.0 (PREMIER Biosoft, Palo Alto, CA, USA) (Table 2). RT-PCR was conducted in a $50-\mu \mathrm{L}$ reaction system containing $2 \mu \mathrm{L}$ of cDNA, $1 \mu \mathrm{L}$ each of forward and reverse primers, $25 \mu \mathrm{L}$ of $2 \times$ Taq PCR StarMix (GenStar, Beijing, China), and $21 \mu \mathrm{L}$ of sterile deionized water in a T100 Thermal Cycler (Bio-Rad, Hercules, CA, USA). The PCR reaction parameters were as follows: $95^{\circ} \mathrm{C}$ for $2 \mathrm{~min} ; 30$ cycles of $95^{\circ} \mathrm{C}$ for $30 \mathrm{~s}, 56{ }^{\circ} \mathrm{C}$ for $30 \mathrm{~s}$, and $72{ }^{\circ} \mathrm{C}$ for $1 \mathrm{~min}$; and a final extension of $72^{\circ} \mathrm{C}$ for $5 \mathrm{~min}$. PCR products were detected by using $1 \%$ agarose gel electrophoresis, recovered by a SanPrep Column DNA Gel Extraction Kit (Sangon Biotech, Shanghai, China), and then ligated into the pMD18-T vector. The ligation products were transformed into E. coli Top10 competent cells for sequencing.

Table 2. Primers for verification and expression analyses of CcDef2.

\begin{tabular}{crc}
\hline Primer Name & Sequence & Primer Usage \\
\hline Def2-F & 5'-ACGCTTCAGTTGAGTCCATCT-3' $^{\prime}$ & Cloning $^{\prime}$ \\
Def2-R & $5^{\prime}$-ACAGTGATCTTTTGGTGTCCACT-3' & \\
Def2-qF & $5^{\prime}$-GCTGTCGCTGTTGTCTACATCGGT-3' & \\
Def2-qR & $5^{\prime}$-CGGCTCTTCTTCGTGGTATGTCTC-3' & RT-qPCR \\
Actin-F & $5^{\prime}$-ACCGCTGAGAGGGAAATCG-3' & \\
Actin-R & 5'-CAAGAAGGAAGGCTGGAAGAG-3' & \\
\hline
\end{tabular}

\subsection{Bioinformatic Analyses}

The open reading frame (ORF) of CcDef2 was predicted with ORFfinder (https: / www. ncbi.nlm.nih.gov/orffinder) (accessed on 6 April 2021) and homology was searched by BLAST against the NCBI "nr" protein database (https: / / blast.ncbi.nlm.nih.gov / Blast.cgi) (accessed on 6 April 2021). The molecular weight and isoelectric point of the CcDef2 peptide were predicted with the ExPaSy ProtParam tool (https:/ / web.expasy.org/protparam) (accessed on 6 April 2021). Dianna 1.1 server (http:/ / clavius.bc.edu/clotelab/DiANNA) (accessed on 6 April 2021) was used to predict disulfide bonds. The phylogenetic tree was con- 
structed by using the neighbor-joining method in the MEGA X software with 1000 replicates. Three-dimensional structure of the mature CcDef2 was predicted with SWISS-MODEL (https: / / swissmodel.expasy.org) (accessed on 15 March 2021) based on homologous modeling and then its molecular graph was drawn using PyMOL 2.5 (Schrodinger, New York, NY, USA).

\subsection{Spatiotemporal Expression Profile}

The mRNA expression levels of CcDef2 at different developmental stages and in various adult tissues were detected by using the CFX96 Real-Time PCR Detection System (Bio-Rad, Hercules, CA, USA). Specific primers specific to CcDef2 for RT-qPCR were designed by Primer Premier 6.0 (PREMIER Biosoft, Palo Alto, CA, USA). RT-qPCR was carried out in a $20-\mu \mathrm{L}$ reaction system that contained $1 \mu \mathrm{L}$ of $\mathrm{cDNA}, 1 \mu \mathrm{L}$ each of forward and reverse primers, $10 \mu \mathrm{L}$ of $2 \times$ SYBR Select Master Mix (Thermo Fisher Scientific, Waltham, MA, USA), and $7 \mu \mathrm{L}$ of sterile deionized water. RT-qPCR was performed with the following parameters: $50{ }^{\circ} \mathrm{C}$ for $2 \mathrm{~min}$; $95^{\circ} \mathrm{C}$ for $2 \mathrm{~min}$; and 40 cycles of $95^{\circ} \mathrm{C}$ for $15 \mathrm{~s}, 60^{\circ} \mathrm{C}$ for $1 \mathrm{~min}$. PCR products were verified by dissociation curve analysis. The $\beta$-actin gene of $C$. chinensis (GenBank accession number: MK370101) was used as the internal control, and the primers used are listed in Table 2. These experiments were repeated three times for each sample.

\subsection{Bacterial Infection Assay}

S. aureus and E. coli were inoculated into $20 \mathrm{~mL}$ Luria-Bertani (LB) medium and cultured in an incubator at $200 \mathrm{rpm}$ at $37^{\circ} \mathrm{C}$. When the $\mathrm{OD}_{600}$ value of the culture reached 0.1 , the bacteria were centrifuged at $10,000 \times g$ for $5 \mathrm{~min}$, and collected and washed with phosphate-buffered saline (PBS, pH 7.5). These two bacteria were mixed and then suspended in PBS to make $\mathrm{OD}_{600}=0.01$. One hundred healthy $C$. chinensis adults were randomly selected for intraperitoneal injection using $1 \mu \mathrm{L}$ of the bacterial suspension. These adults were gathered at 6, 8, 12, 24, 36, 48, 60, and $72 \mathrm{~h}$ after infection and then frozen with liquid nitrogen for standby. The fat bodies were dissected from the adults at $12 \mathrm{~h}$ postinfection. Healthy adult samples were infected with PBS as the control group. Three repeated experiments were performed. Total RNA extraction, cDNA synthesis, and RT-qPCR were performed as described above.

\subsection{Construction of Recombinant Expression Vector}

Due to the small molecular weight of the CcDef2 mature peptide, we employed two flexible linkers (-GGGGSGGGGSGGGGS-) to connect three mature CcDef2 for heterologous expression in order to facilitate the purification and identification of the expressed products. The GenSmar Codon Optimization Tool (Version Beta 1.0) (https: / / www.genscript.com/tools/gensmart-codon-optimization) (accessed on 5 May 2021) was used to optimize the nucleotide sequence of the mature CcDef2 according to the preference of codon usage in E. coli. The optimized sequence was synthesized (Sangon Biotech, Shanghai, China) and then cloned into the pET-28b(+) vector. The recombinant plasmid, pET-28b(+)-CcDef2, was transformed into E. coli TOP10. The bacteria were spread onto LB agar plates containing $50 \mu \mathrm{g} / \mathrm{mL}$ kanamycin and incubated at $37{ }^{\circ} \mathrm{C}$ overnight. Positive clones were identified by three steps, namely PCR, digestion with Nde I and Xho I, and sequencing.

\subsection{Heterologous Expression, Purification and Refolding}

The successfully constructed recombinant plasmid was transformed into E. coli BL21 (DE3) cells. The bacteria were cultured overnight at $37^{\circ} \mathrm{C}$ and a single colony was inoculated into $50 \mathrm{~mL}$ LB liquid medium. When the $\mathrm{OD}_{600}$ value of the bacterial solution reached 0.6 , a final concentration of $0.5 \mathrm{mM}$ IPTG was added. Then the strains were cultured at $20{ }^{\circ} \mathrm{C}$ in a concussive manner for $24 \mathrm{~h}$ and harvested. The bacteria were precipitated by centrifugation at $4{ }^{\circ} \mathrm{C}$ and $4000 \times g$ for $10 \mathrm{~min}$. The bacterial precipitate was resuspended in PBS ( $\mathrm{pH} 7.5$ ) and fragmented by ultrasound on ice. After $20 \mathrm{~min}$ of centrifugation at $4{ }^{\circ} \mathrm{C}$ 
and $10,000 \times g$, the cell disruption precipitate was collected and dissolved in denaturation buffer (pH 7.5 PBS and $8 \mathrm{M}$ urea). The protein samples were detected by sodium dodecyl sulfate-polyacrylamide gel electrophoresis (SDS-PAGE) and then visualized by staining with Coomassie brilliant blue.

According to the above conditions, the expression strains were inoculated into $1000 \mathrm{~mL}$ LB medium and massively cultured. The expressed protein with a $6 \times$ His-tag at the N-terminus was purified using a His-tag Protein Purification Kit (Denaturant-resistant) (Beyotime Biotechnology, Shanghai, China) following the manufacturer's instructions. The concentration of the purified CcDef2 was measured with a BCA Protein Assay Kit (Solarbio, Beijing, China) and $20 \mu \mathrm{L}$ of CcDef2 was subjected to SDS-PAGE. The recombinant protein was identified by Western blot analysis using rabbit anti-His polyclonal antibody (1:800 dilution) as the primary antibody and horseradish peroxidase-conjugated goat antirabbit IgG (1:5000 dilution) as the secondary antibody. The purified CcDef2 protein was dialyzed for $12 \mathrm{~h}$ at $4{ }^{\circ} \mathrm{C}$ in a dialysis bag against $0.4 \mathrm{mM}$ oxidized glutathione, $4 \mathrm{mM}$ reduced glutathione, and decreasing concentrations of urea $(4,2,1$, and $0.1 \mathrm{M})$. The refolded recombinant $\mathrm{CcDef} 2$ was concentrated and stored in Tris- $\mathrm{NaCl}$ buffer $(50 \mathrm{mM}$ Tris and $300 \mathrm{mM} \mathrm{NaCl}, \mathrm{pH} 8.0)$.

\subsection{Antimicrobial Assay}

The antibacterial activity of CcDef2 was determined using the agar plate diffusion method. The inclusion body protein was used as a blank control. Six kinds of bacteria including E. coli, S. typhi, P. aeruginosa, M. luteus, B. subtilis, and S. aureus were picked out with sterilized toothpicks and inoculated into sterile centrifuge tubes containing $1 \mathrm{~mL}$ sterile LB medium without antibiotics, respectively. The bacteria were cultured for $12 \mathrm{~h}$ at $200 \mathrm{rpm}$ and $37^{\circ} \mathrm{C}$. The $100 \mathrm{~mL} \mathrm{MH}$ agar medium was sterilized for $30 \mathrm{~min}$ at $121^{\circ} \mathrm{C}$ and then cooled to $50^{\circ} \mathrm{C}$. Ten microliters of bacterial solution was mixed with $20 \mathrm{~mL}$ of MH agar medium (1:2000) and poured into a $90 \mathrm{~mm}$ petri dish. Holes with a diameter of $6 \mathrm{~mm}$ were drilled in the agar plate using a puncher, and then CcDef2 $(30 \mu \mathrm{g})$ and the inclusion body protein $(30 \mu \mathrm{g})$ were separately added into these holes. After standing at room temperature for $2 \mathrm{~h}$, the plates were incubated at $37^{\circ} \mathrm{C}$ for $24 \mathrm{~h}$ and photographed using a ChemiDoc MP Imaging System (Bio-Rad, Hercules, CA, USA). All tests were independently repeated for three times.

\subsection{MIC Determination of CcDef2}

S. aureus was inoculated onto an $\mathrm{MH}$ agar plate for activation. Single colony that grew well on the plate was selected and inoculated into the $\mathrm{MH}$ broth. The bacteria were cultured at $37{ }^{\circ} \mathrm{C}$ and $200 \mathrm{rpm}$ to the logarithmic growth phase (about $10 \mathrm{~h}$ ) and then harvested by centrifugation at $5000 \mathrm{rpm}$ for $5 \mathrm{~min}$. The strains were washed with sterilized $\mathrm{MH}$ broth and diluted to $10^{5} \mathrm{CFU} / \mathrm{mL}$. The MIC of CcDef2 was determined using the microdilution method. The refolded recombinant CcDef2 $(0.8 \mathrm{mg} / \mathrm{mL})$ was diluted to different concentrations with Tris- $\mathrm{NaCl}$ buffer at $\mathrm{pH}$ 8.0. Aliquots $(100 \mu \mathrm{L})$ of the serial dilutions were dispensed into a 96 well microtiter plate and mixed with $100 \mu \mathrm{L}$ of the bacterial cultures, and Tris- $\mathrm{NaCl}$ buffer instead of protein solution was set as the control. The microtiter plate was incubated at $37^{\circ} \mathrm{C}$ for $18 \mathrm{~h}$ and bacterial growth was measured as absorbance at $600 \mathrm{~nm}$ using a Multiskan GO plate reader (Thermo Fisher Scientific, Waltham, MA, USA). MICs of CcDef2 to the other five kinds of bacteria (E. coli, S. typhi, P. aeruginosa, M. luteus, and B. subtilis) were detected using the same method as above. All tests were independently repeated for three times.

\subsection{Data Analysis}

The expression levels of CcDef2 were calculated using the $2^{-\Delta \Delta C t}$ method at different developmental stages, in various adult tissues, and in adults induced by bacteria. Data were analyzed using SPSS 22.0 statistical software (SPSS Inc., Chicago, IL, USA), and multiple 
comparisons were performed using one-way analysis of variance (ANOVA) and Duncan's multiple range test. A $p$-value less than 0.05 was considered as statistical significance.

\section{Conclusions}

In this study, CcDef2 from C. chinensis was characterized by using molecular cloning procedures, heterologous expression, and functional analysis. We found that the mature CcDef2 has the similar sequence and structural characteristics as most insect defensins, indicating that CcDef2 is conserved during evolution. CcDef2 possesses an excellent inhibitory effect on Gram-positive bacteria and is a highly effective immune effector in the innate immunity of $C$. chinensis. This study provides a theoretical feasibility for the development of AMPs in C. chinensis.

Supplementary Materials: The following supporting information can be downloaded at: https: / / www.mdpi.com/article/10.3390/ijms23052789/s1.

Author Contributions: Investigation, J.D., H.H. and X.-L.Q.; Writing—original draft, T.G. and H.H.; Writing-review and editing, S.-W.L. All authors have read and agreed to the published version of the manuscript.

Funding: This work was supported by the National Natural Science Foundation of China (No. 31560610).

Institutional Review Board Statement: Not applicable.

Informed Consent Statement: Not applicable.

Data Availability Statement: Not applicable.

Conflicts of Interest: The authors declare no conflict of interest.

\section{References}

1. Cytryńska, M.; Wojda, I.; Jakubowicz, T. How insects combat infections. In Lessons in Immunity; Ballarin, L., Cammarata, M., Eds.; Academic Press: Amsterdam, The Netherlands, 2016; pp. 117-128.

2. Hoffmann, J.A. Innate Immunity of Insects. Curr. Opin. Immunol. 1995, 7, 4-10. [CrossRef]

3. Nakhleh, J.; El Moussawi, L.; Osta, M.A. The melanization response in insect immunity. In Advances Insect Physiology; Ligoxygakis, P., Ed.; Academic Press: Cambridge, MA, USA, 2017; pp. 83-109.

4. Nappi, A.J.; Christensen, B.M. Melanogenesis and associated cytotoxic reactions: Applications to insect innate immunity. Insect Biochem. Mol. Biol. 2005, 35, 443-459. [CrossRef] [PubMed]

5. Zug, R.; Hammerstein, P. Wolbachia and the insect immune system: What reactive oxygen species can tell us about the mechanisms of Wolbachia-host interactions. Front. Microbiol. 2015, 6, 1201. [CrossRef] [PubMed]

6. Yi, H.Y.; Chowdhury, M.; Huang, Y.D.; Yu, X.Q. Insect antimicrobial peptides and their applications. Appl. Microbiol. Biotechnol. 2014, 98, 5807-5822. [CrossRef] [PubMed]

7. Lavine, M.D.; Strand, M.R. Insect hemocytes and their role in immunity. Insect Biochem. Mol. Biol. 2002, 32, 1295-1309. [CrossRef]

8. Strand, M.R. The insect cellular immune response. Insect Sci. 2008, 15, 1-14. [CrossRef]

9. Bachère, E. Anti-infectious immune effectors in marine invertebrates: Potential tools for disease control in larviculture. Aquaculture 2003, 227, 427-438. [CrossRef]

10. Bulet, P.; Stöcklin, R.; Menin, L. Anti-microbial peptides: From invertebrates to vertebrates. Immunol. Rev. 2004, 198, 169-184. [CrossRef]

11. Park, Y.; Hahm, K.S. Antimicrobial peptides (AMPs): Peptide structure and mode of action. J. Biochem. Mol. Biol. 2005, 38, 507-516. [CrossRef]

12. Steiner, H.; Hultmark, D.; Engström, A.; Bennich, H.; Boman, H.G. Sequence and specificity of two antibacterial proteins involved in insect immunity. Nature 1981, 292, 246-248. [CrossRef]

13. Lee, J.Y.; Boman, A.; Sun, C.X.; Andersson, M.; Jörnvall, H.; Mutt, V.; Boman, H.G. Antibacterial peptides from pig intestine: Isolation of a mammalian cecropin. Proc. Natl. Acad. Sci. USA 1990, 86, 9159-9162. [CrossRef] [PubMed]

14. Iwasaki, T.; Sakanaka, H.S.; Sagisaka, A.; Asaoka, A.; Taylor, D.M.; Yamakawa, M. A short peptide synthesized on the basis of coleoptericin A from Allomyrina dichotoma shows similar anti-Escherichia coli action. J. Insect Biotechnol. Sericology 2006, 75, 135-139.

15. Cociancich, S.; Dupont, A.; Hegy, G.; Lanot, R.; Holder, F.; Hetru, C.; Hoffmann, J.A.; Bulet, P. Novel inducible antibacterial peptides from a hemipteran insect, the sap-sucking bug Pyrrhocoris apterus. Biochem. J. 1994, 300 Pt 2, 567-575. [CrossRef] [PubMed]

16. Casteels, P.; Ampe, C.; Riviere, L.; Damme, J.C.; Elicone, C.; Fleming, M.; Jacobs, F.; Tempst, P. Isolation and characterization of abaecin, a major antibacterial response peptide in the honeybee (Apis mellifera). Eur. J. Biochem. 1990, 187, 381-386. [CrossRef] 
17. Casteels, P.; Tempst, P. Apidaecin-type peptide antibiotics function through a non-poreforming mechanism involving stereospecificity. Biochem. Biophys. Res. Commun. 1994, 199, 339-345. [CrossRef]

18. Bulet, P.; Urge, L.; Ohresser, S.; Hetru, C.; Otvos, L. Enlarged scale chemical synthesis and range of activity of drosocin, an O-glycosylated antibacterial peptide of Drosophila. Eur. J. Biochem. 1996, 238, 64-69. [CrossRef]

19. Zeya, H.I.; Spitznagel, J.K. Cationic proteins of polymorphonuclear leukocyte lysosomes. I. Resolution of antibacterial and enzymatic activities. J. Bacteriol. 1966, 91, 750-754. [CrossRef]

20. Ganz, T.; Selsted, M.E.; Szklarek, D.; Harwig, S.S.; Daher, K.; Bainton, D.F.; Lehrer, R.I. Defensins. Natural peptide antibiotics of human neutrophils. J. Clin. Investig. 1985, 76, 1427-1435. [CrossRef]

21. Lambert, J.; Keppi, E.; Dimarcq, J.L.; Wicker, C.; Reichhart, J.M.; Dunbar, B.; Lepage, P.; Dorsselaer, A.; Hoffmann, J.; Fothergill, J.; et al. Insect immunity: Isolation from immune blood of the dipteran Phormia terranovae of two insect antibacterial peptides with sequence homology to rabbit lung macrophage bactericidal peptides. Proc. Natl. Acad. Sci. USA 1989, 86, 262-266. [CrossRef]

22. Matsuyama, K.J.; Natori, S.J. Purification of three antibacterial proteins from the culture medium of NIH-Sape-4, an embryonic cell line of Sarcophaga peregrina. J. Biol. Chem. 1988, 263, 17112-17116. [CrossRef]

23. Bals, R.; Goldman, M.J.; Wilson, J.M. Mouse $\beta$-defensin 1 is a salt-sensitive antimicrobial peptide present in epithelia of the lung and urogenital tract. Infect. Immun. 1998, 66, 1225-1232. [CrossRef] [PubMed]

24. Hanaoka, Y.; Yamaguchi, Y.; Yamamoto, H.; Ishii, M.; Nagase, T.; Kurihara, H.; Akishita, M.; Ouchi, Y. In vitro and in vivo anticancer activity of human $\beta$-defensin-3 and its mouse homolog. Anticancer Res. 2016, 36, 5999-6004. [CrossRef] [PubMed]

25. Hassan, M.; Kjos, M.; Nes, I.F.; Diep, D.B.; Lotfipour, F. Natural antimicrobial peptides from bacteria: Characteristics and potential applications to fight against antibiotic resistance. J. Appl. Microbiol. 2012, 113, 723-736. [CrossRef] [PubMed]

26. Cociancich, S.; Ghazi, A.; Hetru, C.; Hoffmann, J.A.; Letellier, L. Insect defensin, an inducible antibacterial peptide, forms voltage-dependent channels in Micrococcus luteus. J. Biol. Chem. 1993, 268, 19239-19245. [CrossRef]

27. Lee, E.; Kim, J.K.; Shin, S.; Jeong, K.W.; Shin, A.; Lee, J.; Lee, D.; Hwang, J.S.; Kim, Y. Insight into the antimicrobial activities of coprisin isolated from the dung beetle, Copris tripartitus, revealed by structure-activity relationships. Biochim. Biophys. Acta 2012, 1828, 271-283. [CrossRef]

28. Mor, A. Peptide-based antibiotics: A potential answer to raging antimicrobial resistance. Drug Dev. Res. 2000, 50, 440-447. [CrossRef]

29. Li, S.W.; Zhao, B.S.; Du, J. Isolation, purification, and detection of the antimicrobial activity of the antimicrobial peptide CcAMP1 from Coridius chinensis (Hemiptera:Dinidoridae). Acta Entomol. Sin. 2015, 58, 610-616. [CrossRef]

30. Broekaert, W.F.; Terras, F.R.G.; Cammue, B.P.A.; Osborn, R.W. Plant defensins: Novel antimicrobial peptides as components of the host defense system. Plant Physiol. 1995, 108, 1353. [CrossRef]

31. Matsuyama, K.J.; Natori, S.J. Molecular cloning of cDNA for sapecin and unique expression of the sapecin gene during the development of Sarcophaga peregrina. J. Biol. Chem. 1988, 263, 17117-17121. [CrossRef]

32. Taylor, K.; Barran, P.E.; Dorin, J.R. Structure-activity relationships in beta-defensin peptides. Biopolymers 2008, 90, 1-7. [CrossRef]

33. Ceřovský, V.; Bém, R. Lucifensins, the insect defensins of biomedical importance: The story behind maggot therapy. Pharmaceuticals 2014, 7, 251-264. [CrossRef] [PubMed]

34. Wang, Y.P.; Lai, R. Insect antimicrobial peptides: Structures, properties and gene regulation. Zool. Res. 2010, 31, 27-34. [CrossRef] [PubMed]

35. Wanniarachchi, Y.A.; Kaczmarek, P.; Wan, A.; Nolan, E.M. Human defensin 5 disulfide array mutants: Disulfide bond deletion attenuates antibacterial activity against Staphylococcus aureus. Biochemistry 2011, 50, 8005-8017. [CrossRef] [PubMed]

36. Tsuji, N.; Battsetsegn, B.; Boldbaatar, D.; Miyoshi, T.; Xuan, X.; Oliver, J.M.; Fujisaki, K. Babesial vector tick defensin against Babesia sp. parasites. Infect. Immun. 2007, 75, 3633-3640. [CrossRef]

37. Wilmes, M.; Cammue, B.P.; Sahl, H.G.; Thevissen, K. Antibiotic activities of host defense peptides: More to it than lipid bilayer perturbation. Nat. Prod. Rep. 2011, 28, 1350-1358. [CrossRef]

38. Dimarcq, J.L.; Hoffmann, D.; Meister, M.; Bulet, P.; Lanot, R.; Reichhart, J.M.; Hoffmann, J.A. Characterization and transcriptional profiles of a Drosophila gene encoding an insect defensin. A study in insect immunity. Eur. J. Biochem. 1994, 221, 201-209. [CrossRef]

39. Thevissen, K.; Warnecke, D.C.; François, I.E.; Leipelt, M.; Heinz, E.; Ott, C.; Zaehringer, U.; Thomma, B.P.; Ferket, K.K.; Cammue, B.P. Defensins from insects and plants interact with fungal glucosylceramides. J. Biol. Chem. 2004, 279, 3900-3905. [CrossRef]

40. Dassanayake, R.S.; Silva Gunawardene, Y.I.; Tobe, S.S. Evolutionary selective trends of insect/mosquito antimicrobial defensin peptides containing cysteine-stabilized $\alpha / \beta$ motifs. Peptides 2007, 28, 62-75. [CrossRef]

41. Meredith, J.M.; Hurd, H.; Lehane, M.J.; Eggleston, P. The malaria vector mosquito Anopheles gambiae expresses a suite of larval-specific defensin genes. Insect Mol. Biol. 2008, 17, 103-112. [CrossRef]

42. Candido-Silva, J.A.; Zanarotti, G.M.; Gallina, A.P.; Almeida, J.C. Developmental regulation of BhSGAMP-1, a gene encoding an antimicrobial peptide in the salivary glands of Bradysia hygida (Diptera, Sciaridae). Genesis 2007, 45, 630-638. [CrossRef]

43. Boman, H.G. Gene-encoded peptide antibiotics and the concept of innate immunity: An update review. Scand. J. Immunol. 1998, 48, 15-25. [CrossRef] [PubMed]

44. Imler, J.L.; Bulet, P. Antimicrobial peptides in Drosophila: Structures, activities and gene regulation. Chem. Immunol. Allergy 2005, 86, 1-21. [CrossRef] [PubMed] 
45. Kanost, M.R.; Jiang, H.; Yu, X.Q. Innate immune responses of a lepidopteran insect, Manduca sexta. Immunol. Rev. 2004, 198, 97-105. [CrossRef] [PubMed]

46. Kumaresan, V.; Bhatt, P.; Ganesh, M.R.; Harikrishnan, R.; Arockiaraj, J. A novel antimicrobial peptide derived from fish goose type lysozyme disrupts the membrane of Salmonella enterica. Mol. Immunol. 2015, 68, 421-433. [CrossRef]

47. Baltzer, S.A.; Brown, M.H. Antimicrobial peptides: Promising alternatives to conventional antibiotics. J. Mol. Microbiol. Biotechnol. 2011, 20, 228-235. [CrossRef]

48. Klüver, E.; Schulz-Maronde, S.; Scheid, S.; Meyer, B.; Forssmann, W.G.; Adermann, K. Structure-activity relation of human beta-defensin 3: Influence of disulfide bonds and cysteine substitution on antimicrobial activity and cytotoxicity. Biochemistry 2005, 44, 9804-9816. [CrossRef]

49. Boulanger, N.; Lowenberger, C.; Volf, P.; Ursic, R.; Sigutova, L.; Sabatier, L.; Svobodova, M.; Beverley, S.M.; Späth, G.; Brun, R.; et al. Characterization of a defensin from the sand fly Phlebotomus duboscqi induced by challenge with bacteria or the protozoan parasite Leishmania major. Infect. Immun. 2004, 72, 7140. [CrossRef]

50. Bulet, P.; Hetru, C.; Dimarcq, J.L.; Hoffmann, D. Antimicrobial peptides in insects; structure and function. Dev. Comp. Immunol. 1999, 23, 329-344. [CrossRef]

51. Ganz, T.; Selsted, M.E.; Lehrer, R.I. Defensins. Eur. J. Haematol. 1990, 44, 1-8. [CrossRef]

52. Lamberty, M.; Ades, S.; Uttenweiler-Joseph, S.; Brookhart, G.; Bushey, D.; Hoffmann, J.A.; Bulet, P. Insect immunity. Isolation from the lepidopteran Heliothis virescens of a novel insect defensin with potent antifungal activity. J. Biol. Chem. 1999, 274, 9320-9326. [CrossRef]

53. Lowenberger, C.; Bulet, P.; Charlet, M.; Hetru, C.; Hodgeman, B.M.; Christensen, B.; Hoffmann, J.A. Insect immunity: Isolation of three novel inducible antibacterial defensins from the vector mosquito, Aedes aegypti. Insect Biochem. Mol. Biol. 1995, 25, 867-873. [CrossRef]

54. Kaushal, A.; Gupta, K.; van Hoek, M.L. Characterization of Cimex lectularius (bedbug) defensin peptide and its antimicrobial activity against human skin microflora. Biochem. Biophys. Res. Commun. 2016, 470, 955-960. [CrossRef] [PubMed]

55. Wei, L.; Mu, L.X.; Wang, Y.P.; Bian, H.; Li, J.; Lu, Y.L.; Han, Y.; Liu, T.; Lv, J.; Feng, C.P.; et al. Purification and characterization of a novel defensin from the salivary glands of the black fly, Simulium bannaense. Parasit. Vectors 2015, 8, 71. [CrossRef]

56. Wilde, C.G.; Griffith, J.E.; Marra, M.N.; Snable, J.L.; Scott, R.W. Purification and characterization of human neutrophil peptide 4, a novel member of the defensin family. J. Biol. Chem. 1989, 264, 11200-11203. [CrossRef]

57. Valore, E.V.; Park, C.H.; Quayle, A.J.; Wiles, K.R.; McCray, P.B.; Ganz, T. Human $\beta$-defensin-1: An antimicrobial peptide of urogenital tissues. J. Clin. Investig. 1998, 101, 1633-1642. [CrossRef] [PubMed]

58. Harder, J.; Bartels, J.; Christophers, E.; Schröder, J.M. A peptide antibiotic from human skin. Nature 1997, 387, 861. [CrossRef]

59. Starner, T.D.; Agerberth, B.; Gudmundsson, G.H.; McCray, P.B. Expression and activity of beta-defensins and LL-37 in the developing human lung. J. Immunol. 2005, 174, 1608. [CrossRef]

60. Su, T.; Mulla, M.S. Quantitative determination of free amino acids in the hemolymph of autogenous and anautogenous strains of Culex tarsalis (Diptera: Culicidae). J. Med. Entomol. 1997, 34, 729-734. [CrossRef] 